\title{
A Viscoelastic Traction Layer Model of Muco-Ciliary Transport*
}

\author{
D. J. Smith, E. A. Gaffney, J. R. Blake
}

School of Mathematics, University of Birmingham, Birmingham B15 2TT, UK

Published online: 23 February 2007

(C) Society for Mathematical Biology 2007

In the html abstract portion of the online publication of "A Viscoelastic Traction Layer Model of Muco-Ciliary Transport" (DOI: 10.1007/s11538-005-9036-x) the last name of the first author was mistakenly stated. The authors' names should have appeared as above. Springer regrets the error.

${ }^{*}$ The online version of the original article can be found at http://dx.doi.org/ 10.1007/s11538-005-9036-x 